\section{Experiência de Doença e Narrativa}

Miriam Cristina Rabelo, Paulo César Alves e Iara Maria Souza. Rio de Janeiro: Editora Fiocruz, 1999. 264 páginas

"we must try to understand how vision can be brought into being somewhere without being enclosed in its perspective" (Merleau-Ponty, 1962, p. 67) ${ }^{l}$

O olhar antropológico sobre temas específicos na área de saúde e, especificamente, na saúde mental, geralmente revela uma interlocução possível e, ao mesmo tempo, instigante entre a antropologia médica e a biomedicina. Essa interlocução é favorecida à medida que ambas buscam revelar a complexidade da experiência simbólica dos seres humanos, segundo Duarte (1998). ${ }^{2}$ No entanto, a especificidade de suas lógicas explicativas e as diferentes perspectivas em jogo são afirmadas, segundo limites de uma possível complementaridade. Desse diálogo e das possíveis trocas entre ambas as ciências, delineia-se, certamente, um campo mais amplo para o conhecimento sobre os diferentes aspectos da saúde e da doença mental, à medida que são desvendados alguns dos enigmas da própria existência humana.

"Experiência de Doença e Narrativa" é um livro que permite captar uma das dimensões do encontro entre a antropologia médica e a biomedicina, ao tomar, como ponto de parti$\mathrm{da}$, a atualidade e a complexidade de discussões sobre a periferia urbana, em que se misturam aos aspectos biomédicos da saúde e da doença mental outros elementos de ordem socioeconômica e cultural, como formas de ocupação urbana, a pobreza, a migração, a religiosidade, os dramas individuais e coletivos, os quais têm sido objeto de estudos que enfocam a relação entre saúde mental e urbanização, conforme Harpham \& Blue (1995). ${ }^{3}$

Analisando como fio condutor a experiência, a riqueza da pesquisa etnográfica encontra-se retratada em cada uma das páginas desse livro como uma janela que se abre para o "mundo de fora", o mundo real do Nordeste de Amaralina - bairro de classe trabalhadora de Salvador - e de pessoas que vivem a aflição da doença mental em suas experiências cotidianas, porque são doentes ou porque, como membros da família e da comunidade, convivem com os mesmos.

A pesquisa é sistematizada no livro em duas partes:

- primeira: trata da construção social e cultural da doença mental, a partir de experiências de aflição, ou seja, dos significados e das práticas relativas à doença mental, principalmente segundo os membros da comunidade, familiares e vizinhos;

- segunda: focaliza os indivíduos doentes na heterogeneidade e na especificidade de suas experiências de adoecimento e de tratamento.

Por meio da pesquisa etnográfica, a descrição sobre os processos de adoecimento e de tratamento dos transtornos mentais adquire vida fundamentalmente na voz, sob a forma de narrativa, daqueles que compartilham a experiência de identificar, explicar e reagir à doença mental.

$\mathrm{Na}$ análise, os autores fundamentam-se, principalmente, nas teorias sociológicas de base fenomenológica e hermenêutica, com ênfase aos aspectos relacionais à experiência e à ação. Sem a pretensão de assumir uma única perspectiva, os autores delimitam o campo teórico

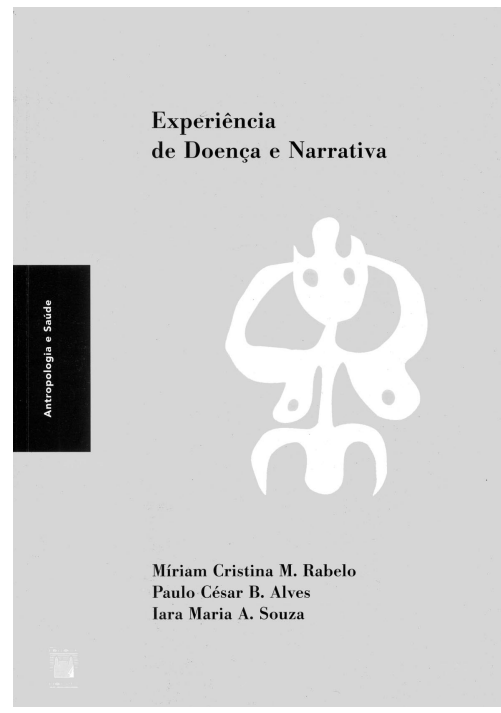
preponderante nas aná-

lises, diferenciando-o de outras análises, como a perspectiva biomédica, que trata dos aspectos orgânicos dos processos de doença, de cura ou de estudos nas ciências sociais que ressaltam os aspectos ideais ou simbólicos desse processo ou também de modelos explicativos da perspectiva estruturalista que, segundo Alves \& Souza, " "não leva em conta o contexto intencional, circunstancial e dialógico em que os indivíduos desenvolvem suas ações" (ib., p. 131).

Segundo a perspectiva fenomenológica, as percepções e as interpretações sobre o mundo e a existência ocorrem somente em termos de uma compreensão vivida e, portanto, experimental de "ser no mundo", em que o corpo assume papel fundamental. É por meio do corpo que é revelado o "ser no mundo", e não do exterior, ou seja, é a partir de uma consciência sobre o corpo que se inscrevem e se revelam as várias dimensões da vida com todas suas contradições e seus conflitos. Nessa experiência corporal, as diferentes concepções e as práticas relacionadas à saúde e à doença mental são percebidas, criadas e recriadas com interação dinâmica estabelecida entre os indivíduos, conflitos e negociações, em um (con)texto das redes de relações socioculturais que compartilham.

Sempre enfatizando a relação entre os sujeitos, as narrativas reportam-se ao tempo e ao espaço essenciais à compreensão das experiências de aflição mental. O tempo da doença - tempo socialmente inscrito - e do espaço/contexto da pluralidade dos acontecimentos e das relações sociais estabelecem as referências culturais que permitem o suporte aos doentes mentais ou a sua "evitação" e o seu estigma e, também, a adesão a determinadas formas de tratamento, numa constante troca e negociação dos significados, conforme já mencionado.

Cada um dos textos apresentados revela a riqueza das múltiplas experiências, destacadas pela análise teórica que permite lançar um novo olhar sobre a questão. Assim, os autores apresentam a possibilidade de adentrar outros mundos. Também descortina-se a possibilidade de ampliar a compreensão dos 
fenômenos relacionados à saúde e à doença mental, à medida que "a reflexão sobre a natureza dos fenômenos patológicos ou sobre os critérios que o definem recoloca o problema da doença, tanto orgânica quanto mental, no âmbito das relações sociais que a engendram e determinam" (Montero, 1985:66). ${ }^{5}$

Como os autores apontam, a intenção da análise não é sobrepor uma perspectiva em detrimento de outras, mas reconhecer os múltiplos olhares em busca da compreensão da existência humana e das aflições que lhe acometem. Nesse sentido, a análise sobre os processos de saúde e de doença mental torna-se mais completa à medida que reconhece as múltiplas e variadas perspectivas, e a interface estabelecida entre a psiquiatria e a cultura é uma evidência da possibilidade infinita de diálogos e de negociações, em se tratando da percepção da vida social e do próprio discurso sobre o social.

Eunice Nakamura

Universidade de São Paulo, SP, Brasil

\section{Referências}

1. Merleau-Ponty M. Experience and objective thought. The problem of the body. In: The Phenomenology of perception. Editora Routledge. London, NY; 1962.

2. Duarte LFD. A antropologia médica pede passagem. Colóquio; 1998. p. 33-8.

3. Harpham T, Blue I, editors. Urbanization and mental health in developing countries. England: Avebury; 1995.

4. Alves PC e Souza, IM. Escolha e avaliação de tratamento para problemas de saúde: considerações sobre o itinerário terapêutico. In: Rabelo, Miriam Cristina; Alves, Paulo César e Souza Iara Maria. Experiência de Doença e Narrrativa. Editora Fiocuz. Rio de Janeiro; 1999. p. $125-38$

5. Montero P. Da doença à desordem: a magia na umbanda. Rio de Janeiro: Graal; 1985. 